\title{
PKM Pelatihan Sistem Informasi Berbasis Microsoft Office Guna Meningkatkan Softskill Anggota dalam Membuat Laporan Keuangan pada BKM Maju Makmur Kajeksan Sidoarjo
}

Oleh :

Laely Aghe Africa ${ }^{1)}$, Dian Oktarina ${ }^{2)}$, Agustinus Kismet Nugroho Jati ${ }^{3)}$, Immanuel Candra Irawan $^{4)}$, Sholikha Oktavi Khalifaturofiah ${ }^{5)}$

Universitas Hayam Wuruk Perbanas

E-mail : laely.aghe@perbanas.ac.id ${ }^{1)}$,dian.oktarina@perbanas.ac.id ${ }^{2)}$, agustinus.kismet@perbanas.ac.id ${ }^{3)}$, Immanuel.candra@perbanas.ac.id ${ }^{4)}$, sholikha.oktavi@perbanas.ac.id ${ }^{5)}$

\begin{abstract}
Abstrak
Badan Keswadayaan Masyarakat (BKM) Maju Makmur di Desa Kajeksan Jawa Timur merupakan mitra dalam kegiatan Pengabdian Masyarakat yang memerlukan pelatihan dalam hal peningkatan Softskill bagi anggota agar dapat membuat laporan keuangan yang lebih bagus dan terstruktur. Hasil akhir yang diutamakan dalam kegiatan ini adalah bahwa anggota BKM Maju Makmur mampu membuat Laporan Keuangan yang tersistem dan kedepannya dapat dijadikan dokumen pendukung ketika BKM Maju Makmur mengajukan pendanaan kepada salah satu Bank, sehingga dapat membuka lapangan kerja baru. Hasil akhir yang ingin dicapai dalam kegiatan Pengabdian Masyarakat ini adalah Publikasi Jurnal Nasional 2021 dan video kegiatan terkait dengan pemberian pelatihan dan yang paling utama adalah kemampuan anggota BKM dalam mengaplikaskan hasil dari pelatihan Microsoft Office.
\end{abstract}

Kata Kunci: Microsotf Office, Laporan Keuangan, Badan Keswadayaan Masyarakat, Kajeksa

\section{Pendahuluan}

Pengetahuan tentang teknologi informasi dan pemanfaatannya menjadi suatu hal yang vital, seiring semakin meluasnya peningkatan kebutuhan ketersediaan informasi yang akurat dan cepat (Apriyansyah, Maullidina, \& Purnomo, 2018). Hal ini merupakan salah satu modal utama untuk dapat bersaing di era globalisasi, baik masa kini maupun masa depan.
Karena itu, pengetahuan dan pemanfaatan teknologi informasi menjadi suatu kebutuhan baik bagi individu, kelompok, maupun instansi. Hal ini disebabkan karena hampir seluruh kegiatan sehari-hari tidak lepas dari bantuan teknologi informasi. Salah satu bentuk teknologi informasi yang dapat membantu kegiatan sehari yaitu melalui aplikasi komputer. Aplikasi komputer banyak digunakan 
terutama pada dunia bisnis. Penggunaan aplikasi komputer pada bisnis memberikan banyak manfaat antara lain dapat memberikan efisiensi waktu, biaya, dan tenaga, mengurangi tingkat kesalahan hingga meningkatkan kualitas pelaporan keuangan bisnis.

Pemanfaatan teknologi informasi tersebut sangat dibutuhkan dalam tata kelola bisnis, khususnya bisnis yang dijalankan oleh kelompok masyarakat. Salah satu bentuk bisnis kelompok masyarakat adalah Badan Keswadayaan Masyarakat (BKM) pada tingkat desa. Dengan memanfaatkan teknologi informasi, program-program bisnis kelompok masyarakat ini dapat berjalan lebih efisien dan tepat sasaran. Selain itu, dengan penggunaan aplikasi komputer yang tepat, laporan keuangan bisnis menjadi lebih berkualitas. Peningkatan kualitas bisnis kelompok masyarakat desa ini secara tidak langsung akan meningkatkan pula taraf hidup masyarakat desa tersebut. Hal ini merupakan bagian dari upaya pembangunan desa seperti yang diamanahkan dalam undang-undang.

Kutipan pada Undang-Undang Nomor 6 Tahun 2014 Tentang Desa, antara lain : Pembangunan Desa adalah upaya peningkatan kualitas hidup dan kehidupan untuk sebesarbesarnya kesejahteraan masyarakat Desa. Kawasan Perdesaan adalah kawasan yang mempunyai kegiatan utama pertanian, termasuk pengelolaan sumber daya alam dengan susunan fungsi kawasan sebagai tempat permukiman perdesaan, pelayanan jasa pemerintahan, pelayanan sosial, dan kegiatan ekonomi. Keuangan Desa adalah semua hak dan kewajiban Desa yang dapat dinilai dengan uang serta segala sesuatu berupa uang dan barang yang berhubungan dengan pelaksanaan hak dan kewajiban Desa. Aset Desa adalah barang milik Desa yang berasal dari kekayaan asli Desa, dibeli atau diperoleh atas beban Anggaran Pendapatan dan Belanja Desa atau perolehan hak lainnya yang sah. Pemberdayaan Masyarakat Desa adalah upaya mengembangkan kemandirian dan kesejahteraan masyarakat dengan meningkatkan pengetahuan, sikap, keterampilan, perilaku, kemampuan, kesadaran, serta memanfaatkan sumber daya melalui penetapan kebijakan, program, kegiatan, dan pendampingan yang sesuai dengan esensi masalah dan prioritas kebutuhan masyarakat Desa. Pada pengabdian ini kami 
menggunakan BKM (Badan

Keswadayaan Masyarakat)

Simpan Pinjam, Usaha Token dan Pulsa merupakan beberapa contoh dari jasa yang diberikan oleh Badan Keswadayaan Masyarakat yang ada di Desa Kajeksan, Sidoarjo, Jawa, dan berdasarkan koordinasi dengan mitra melalui media online, diketahui bahwa mitra membutuhkan softskill dibidang sistem terutama yang berkaitan dengan pembuatan laporan keuangan yaitu Microsoft Excell dan Microsoft Word. Secara garis besar sekitar ada $30 \%$ anggota BKM yang berpendidikan Sarjana dan sisanya sekitar $70 \%$ anggota BKM adalah masih dari jenjang SMA. Oleh karena itu masih diperlukan adanya program pelatihan terkait dengan penguasaan sistem.

\section{Metode Pelaksanaan}

Pelaksanaan

program

Pengabdian Masyarakat ini menggunakan metode pelatihan, diskusi, umpan balik kepada peserta ke wilayah Desa Kajeksan, Sidoarjo, Jawa Timur. Pelatihan difokuskan pada beberapa aplikasi komputer yaitu Microsoft Excel dan Microsoft Word.

\section{Hasil Dan Pembahasan}

Berdasarkan jadwal kegiatan pengabdian masyarakat yang telah di rencanakan, maka kami tim pengabdian masyarakat telah melaksanakan pendampingan pada hari Sabtu tanggal 19 Desember 2020 dari mulai pukul 08.00 WIB sampai dengan pukul 13.00 WIB. Kegiatan yang dilakukan adalah melakukan pendampingan secara online melalui media Zoom karena pada kondisi yang tidak memungkinkan bagi kami yang disebabkan oleh adanya pandemic atau wabah covid19 maka tim Pengabdian Masyarakat melaksankan pendampingan secara langsung disaat awal pemberlakuan WFH (Work From Home) dimana kami sebagai tim pelaksana pengabdian masyarakat melaksanakan pendampingan dari rumah masing-masing.

Hasil dari pendampingan adalah bahwa BKM Maju Makmur mencoba membuat laporan keuangan secara sistem namun, saat ini yang dapat dilakukan adalah merapikan pencatatan yang ada dalam proses keuangan BKM karena kondisi yang belum memungkinkan untuk dilaksanakan secara maksimal

Berikut ini kami lampirkan foto atau dokumentasi dari 
Jurnal Abdiraja

ISSN : 2621-9379 (Online)

Volume 4, Nomor 2, September 2021

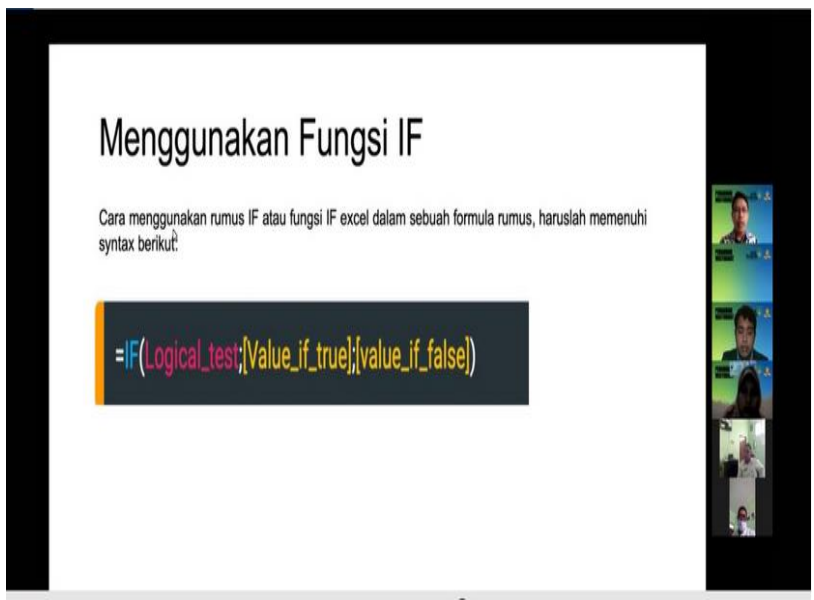

Gambar 4 : Penjelasan Materi (3)

Gambar 1 : Diskusi awal

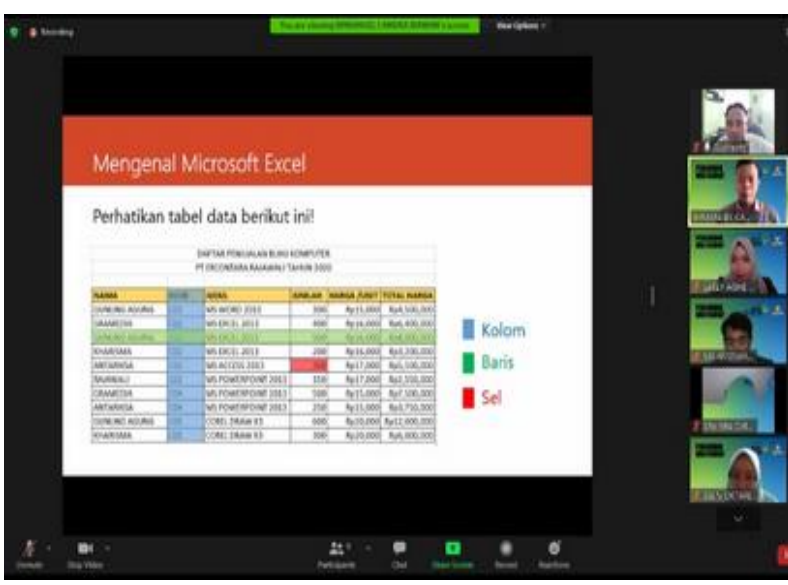

Gambar 2 : Penjelasan Materi (1)

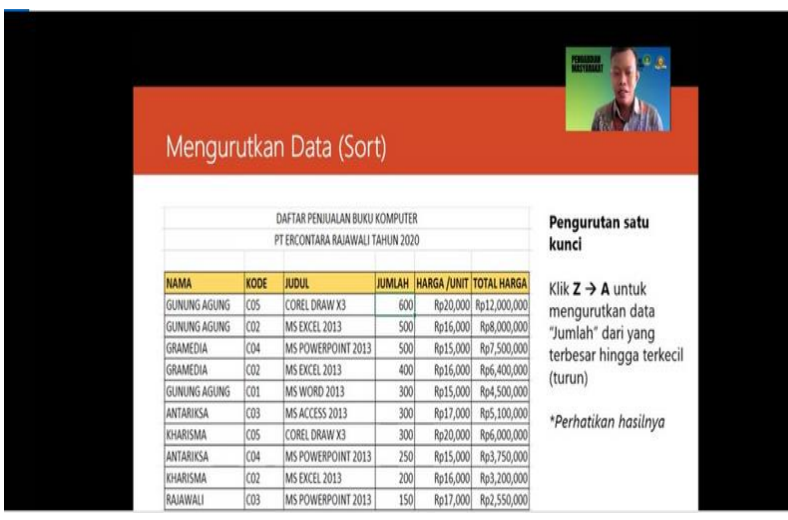

\section{Kesimpulan}

Saat covid 19 masih dalam kategori penyebaran yang sangat luas, namun tidak menutup tim kami untuk melaksanakan pengabdian dengan melalui media apapun, dan pada akhirnya BKM Maju Makmur Kajeksan dapat membuat laporan keuangan yang tersistem dan teratur. Dan salah satu output dari tim pengabdian masyarakat adalah berupa SOP dalam menjalankan program excel yang berguna untuk membuat laporan keuangan, berikut tampilan beberapa SOP yang ada :

Gambar 3 : Penjelasan Materi (2) 
Jurnal Abdiraja

ISSN : 2621-9379 (Online)

Volume 4, Nomor 2, September 2021

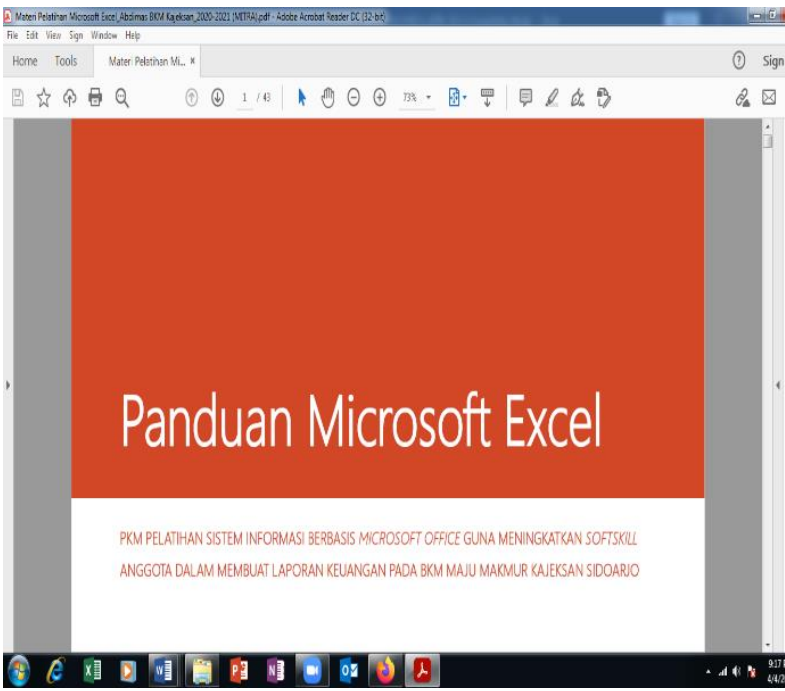

Gambar 5 : SOP untuk BKM

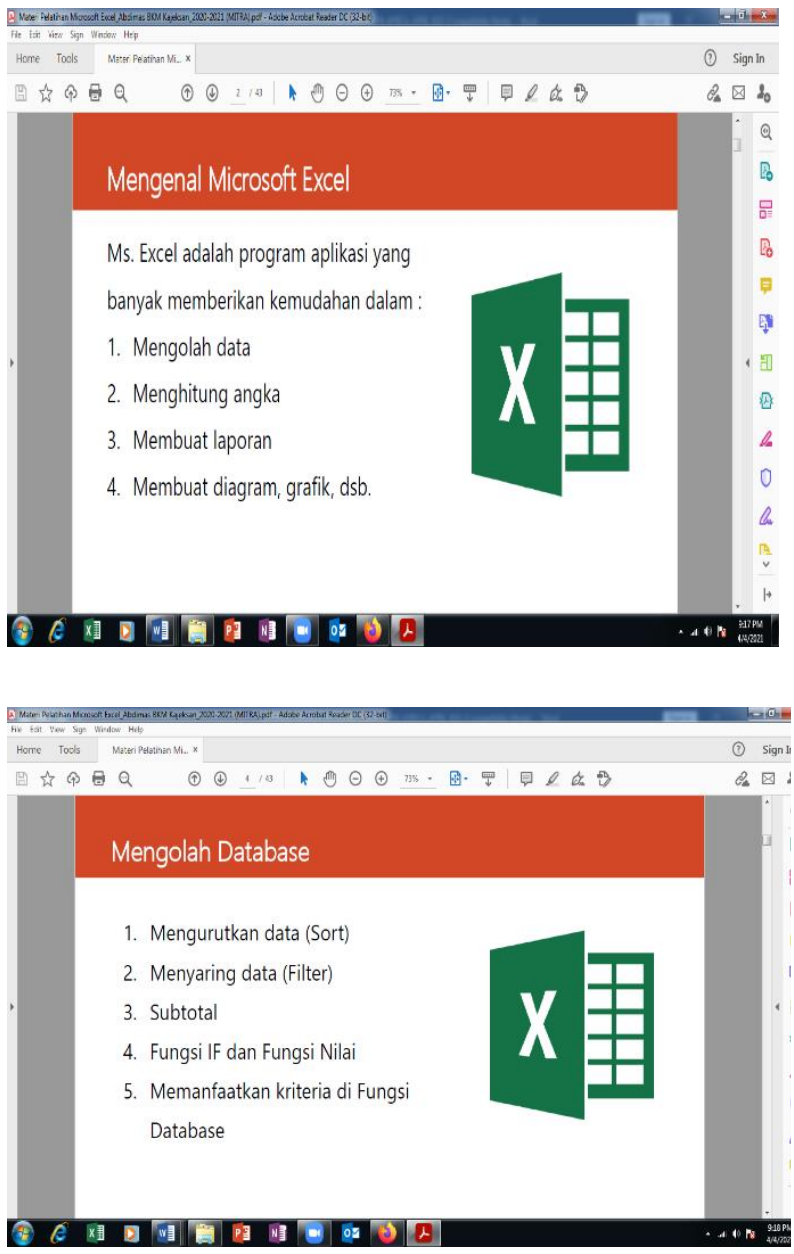

Gambar 6 : Bagian dari SOP BKM (1)

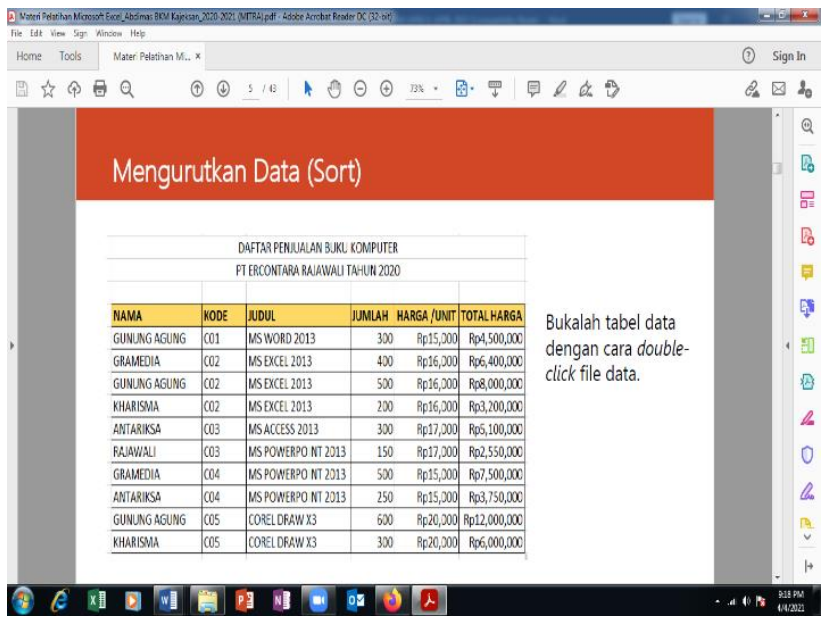

Gambar 7 : Bagian dari SOP BKM (2)

\section{DaftarPustaka}

Undang-Undang No.6 Tahun 2014

Tentang Desa

Apriyansyah, Maullidina, I., \& Purnomo, E. P. (2018, Juni). Efektivitas Sistem Informasi Desa (SID) Dalam Pelayanan Publik Di Desa Dlingo, Kecamatan Dlingo, Kabupaten Bantul. Jurnal Analisis Kebijakan dan Pelayanan Publik, 4(1), 10-24 